\title{
Ceruminous Gland Carcinomas: A Clinicopathologic and Immunophenotypic Study of 17 Cases
}

\author{
Nikhil Crain · Brenda L. Nelson • E. Leon Barnes • \\ Lester D. R. Thompson
}

Received: 13 October 2008/Accepted: 18 November 2008/Published online: 3 December 2008

(C) The Author(s) 2008. This article is published with open access at Springerlink.com

\begin{abstract}
Background Ceruminal gland carcinomas are rare neoplasms confined to the skin lining the cartilaginous part of the external auditory canal. Design Retrospective. Results The patients included 11 men and 6 women, aged 33-82 years (mean, 59.5 years). Patients presented clinically with a mass of the outer half of the external auditory canal $(n=14)$, hearing changes $(n=5)$, drainage $(n=4)$, or paralysis of the facial nerve $(n=3)$. The polypoid masses ranged in size from 0.5 to $3 \mathrm{~cm}$ in greatest dimension (mean, $1.8 \mathrm{~cm}$ ). Histologically, the tumors demonstrated a solid to cystic pattern, composed of an infiltrating glandular to cribriform arrangement of epithelial cells. Histologic features included a dual cell population (although not the dominant histology), increased cellularity, moderate to severe nuclear pleomorphism, irregular nucleoli, increased mitotic figures (mean, $3 / 10 \mathrm{HPF}$ ), including atypical forms, and tumor necrosis $(n=2)$. Tumors were divided into three types of adenocarcinoma based on pattern of growth and cell type (ceruminous, NOS $[n=12]$, adenoid cystic $[n=4]$, mucoepidermoid $[n=1])$. CK7 and CD117 highlighted the luminal cells, while S1-00 protein showed a predilection for the basal cells of ceruminous and adenoid cystic
\end{abstract}

N. Crain · L. D. R. Thompson $(\bowtie)$

Department of Pathology, Southern California Permanente

Medical Group, Woodland Hills Medical Center, 5601 De Soto

Avenue, Woodland Hills, CA 91367-6701, USA

e-mail: Lester.D.Thompson@kp.org

B. L. Nelson

Pathology Department, Naval Medical Center, San Diego, CA, USA

E. L. Barnes

Department of Pathology, Presbyterian University Hospital, Pittsburgh, PA, USA carcinomas. Metastatic adenocarcinoma or direct extension from salivary gland neoplasms are the principle differential considerations. Surgical resection was used in all patients with radiation used in four patients. Eleven patients were alive or had died of unrelated causes without evidence of disease (mean, 11.2 years); six patients had died with disease (mean, 4.9 years), all of whom had developed local recurrence. Conclusion Ceruminous-type carcinomas, with the exception of ceruminous mucoepidermoid carcinoma, all demonstrated a dual cell population of basal myoepithelial-type cells and luminal apocrine cells. The specific histologic sub-type does not influence the long-term patient outcome.

Keywords Ear - Ceruminal - Ceruminous · Gland . Carcinoma - Adenoid cystic - Mucoepidermoid . Immunohistochemistry $\cdot$ Prognosis

\section{Introduction}

Tumors arising from the ceruminal glands of the external ear canal can present a diagnostic dilemma because of their varied clinical and histological manifestations. While common in other animals [1], tumors of this type are rare in humans and therefore are seldom seen by general surgical pathologists [2, 3]. In fact, glandular external auditory canal tumors represent $0.00025 \%$ of all cases at one large referral institution [4], and represented $2.4 \%$ of all ear neoplasms at our referral institution. Further adding to the confusion for pathologists and clinicians alike, is the variable nomenclature used to synonymously describe both benign and malignant tumors of ceruminal gland origin (Table 1) [5-16]. The varied clinical behavior, treatment alternatives, and long-term patient prognosis of the 
Table 1 Synonyms that have been used for ceruminous neoplasms of the external auditory canal [5-16]

Ceruminoma (ceruminomata)
Hidroadenoma
Adenoid cystic carcinoma
Adenocarcinoma of ceruminal type
Mucoepidermoid carcinoma
Syringocystadenoma papilliferum
Pleomorphic adenoma
Ceruminal adenoma
Mixed tumor of skin
Ceruminous adenoma
Cylindroma
Adenoma ceruminalis
Myoepithelioma
Clear cell carcinoma
Aural hidradenoma
Chondroid syringoma
Eccrine cylindroma (cutaneous eccrine cylindroma)
Cylindromatous lymphangioma
Cylindromatous deep hidradenoma

different types of ceruminal gland neoplasms necessitates more specific diagnostic terminology. While there have been a few series a few decades ago [4, 9, 17, 18], there are only a limited number of case reports in the English literature (Table 2), which is otherwise devoid of a large comprehensive evaluation of ceruminous-type adenocarcinomas with respect to their histomorphology, immunohistochemical reactivity, treatment outcomes, and clinical behavior. We undertook this study in an attempt to identify any specific features which can be used to separate benign from malignant ceruminous tumors and to determine the best nomenclature to yield a meaningful clinical management impact.

\section{Methods}

The records of 17 patients with tumors diagnosed as ceruminal adenocarcinoma, ceruminal adenoid cystic carcinoma, mucoepidermoid carcinoma, and adenocarcinoma of the external ear canal were selected. The cases were retrieved from the files of the Otorhinolaryngic-Head \& Neck Tumor Registry of the Armed Forces Institute of Pathology (AFIP), Washington, DC, between 1970 and 2000. These 17 cases were chosen from a review of 723 (2.4\%) benign or malignant primary ear tumors seen in consultation during this time. Due to the nature of our consultation service, we were not able to separate tumors arising from the external ear versus external auditory canal in attempting to determine the incidence data. Suffice it to say that ceruminal malignancies are uncommon. Fifteen cases were obtained from civilian sources, including university medical centers and foreign contributors, one case from a military hospital, and one case from a Veterans Administration medical center.

Materials within the Institute's files were supplemented by a review of the patient demographics (gender, age); symptoms and physical findings and duration at presentation including mass, hearing loss, bleeding, infection, pain, headaches, weakness, syncope or dizziness, nerve paralysis, discharge, equilibrium changes, tinnitus and/or popping, visual changes; and past medical and surgical history. In addition, we reviewed radiographic, surgical pathology, and operative reports and obtained follow-up information from oncology data services by written questionnaires or direct communication with the treating physician(s) or the patient. Follow-up data, available for all patients, included information regarding tumor location, presence of recurrent disease, treatment modalities used, and the current patient status. This clinical investigation was conducted in accordance and compliance with all statutes, directives, and guidelines of the Code of Federal Regulations, Title 45, Part 46, and the Department of Defense Directive 3216.2 relating to human subjects in research.

The macroscopic pathology observations noted within this study were gathered from the individual gross descriptions of the neoplasms given by the contributing pathologists. Hematoxylin and eosin-stained slides from all cases were reviewed, with specific histologic features annotated as follows: exact tumor location; lateralization; tumor size (greatest dimension in centimeters); tumor encapsulation (presence or absence); tumor extension (mastoid bone, eustachian tube, and/or middle ear); architectural pattern of growth (solid, papillary, cystic infiltrating, glandular); dual cell population; surface origin; surface ulceration; presence or absence of necrosis; tumor cellularity (low, moderate, or high); cellular pleomorphism (mild, moderate, severe); presence of nucleoli; mitotic figures (number of mitotic figures per 10 high power fields [magnification at $\times 40$ with a $\times 10$ objective lens using an Olympus BX40 microscope]); atypical mitotic figures (present or absent, and defined by abnormal chromosome spread, tripolar or quadripolar forms, circular forms, or indescribably bizarre); ceruminal apocrine decapitation secretion; cerumen (wax) eosinophilic to brown granules in the cytoplasm; and the presence of other microscopic pathologic findings in the remaining tissues.

Immunophenotypic analysis was performed in all cases with suitable material by a standardized Envision ${ }^{\mathrm{TM}}$ method employing $4 \mu \mathrm{m}$-thick, formalin fixed, paraffin embedded sections. Table 3 documents the pertinent, 
Table 2 Review of the English literature on ceruminal adenocarcinoma $[4,5,10,12$, $14,16-18,29-32,38-66]^{\mathrm{a}}$
Characteristics

Ceruminous carcinoma

Total: $N=91$

$\begin{array}{ll}\text { Gender } & \\ \text { Women } & 54 \\ \text { Men } & 37\end{array}$

Age (in years)

Range $\quad 21-92$

$\begin{array}{ll}\text { Mean } & 49.0\end{array}$

$\begin{array}{ll}\text { Women (mean) } & 49.7\end{array}$

$\begin{array}{ll}\text { Men (mean) } & 48.0\end{array}$

Symptom duration (in months) ${ }^{\mathrm{b}}$

Range $\quad 1-444$

Mean $\quad 51.6$

Women (mean) $\quad 41.7$

$\begin{array}{ll}\text { Men (mean) } & 64.4\end{array}$

Symptoms at presentation ${ }^{\mathrm{b}, \mathrm{c}}$

Pain (otalgia) $\quad 48$

$\begin{array}{ll}\text { Mass } & 34\end{array}$

Hearing changes (loss, tinnitus) 33

Drainage, discharge, bleeding 31

$\begin{array}{ll}\text { Nerve changes (paralysis, paresthesias) } & 7\end{array}$

Location $(n=72)^{\mathrm{b}}$

Left $\quad 39$

$\begin{array}{ll}\text { Right } & 33\end{array}$

Size (in $\mathrm{cm})^{\mathrm{b}}$

Range $\quad 0.5-3.0$

Mean $\quad 1.41$

Median 1.3

Tumor histology:

$\begin{array}{ll}\text { Adenoid cystic carcinoma } & 64\end{array}$

Adenocarcinoma, ceruminous $\quad 22$

Mucoepidermoid carcinoma $\quad 4$

Sebaceous carcinoma 1

All patients with follow-up $(n=81)$ (months) 83.9 (mean)

$\begin{array}{ll}\text { Follow-up range } & 1-348\end{array}$

Alive, no evidence of disease $(n=37) \quad 68.6(5.7$ years $)$

Alive, with disease $(n=13) \quad 108.5$ (9.0 years)

Dead, no evidence of disease $(n=6) \quad 154.0$ (12.8 years)

Dead, with disease $(n=25) \quad 77.0$ (6.4 years)

Alive/Dead, no evidence of disease $(n=43) \quad 80.5$ (6.7 years)

Alive/Dead, with disease $(n=38) \quad 87.7$ (7.3 years)

Patient outcome by tumor histology: ${ }^{\mathrm{b}}$

Adenocarcinoma, ceruminous $^{\mathrm{b}}(n=20) \quad 55.9$ (4.7 years)

Adenoid cystic carcinoma ${ }^{\mathrm{b}}(n=56) \quad 99.8$ (8.3 years)

Mucoepidermoid carcinoma $^{\mathrm{b}}(n=4) \quad 18.5$ (1.5 years)

$\begin{array}{ll}\text { Patient outcome for patients with recurrence }(n=49) & 102.6 \text { (8.5 years) }\end{array}$

Patient outcome for patients without recurrence $(n=32) \quad 55.3$ (4.6 years) c Patients may have experienced more than one symptom proteolytic antigen retrieval was performed by predigestion for 3 min with $0.05 \%$ Protease VIII (Sigma Chemical Co.,

St. Louis, MO) in a $0.1 \mathrm{M}$ phosphate buffer, $\mathrm{pH}$ of 7.8 , at commercially available immunohistochemical antibody panel used. The analysis was performed on a single representative block for each primary tumor. When required, 
Table 3 Immunohistochemical panel

\begin{tabular}{llllc}
\hline Antigen/antibody & $\begin{array}{l}\text { Primary } \\
\text { antibody }\end{array}$ & Company & Dilution & Cellular conditioning \\
\hline $\begin{array}{l}\text { Cytokeratin } \\
\text { (AE1/AE3 and LP34) }\end{array}$ & $\mathrm{mm}$ & $\begin{array}{c}\text { Boehringer Mannheim Biochemicals, } \\
\text { Indianapolis, IN, and Dako, Carpinteria, CA }\end{array}$ & $\begin{array}{l}1: 50 \\
1: 200\end{array}$ & Protease digestion \\
Epithelial membrane antigen (EMA) & $\mathrm{mm}$ & Ventana, Tucson, AZ & Neat & Protease digestion \\
CK7 & $\mathrm{mm}$ & Dako & $1: 400$ & Protease digestion \\
CK5/6 & $\mathrm{mm}$ & Dako & $1: 20$ & Steam \\
CK20 & $\mathrm{mm}$ & Dako & $1: 200$ & none \\
S-100 protein & $\mathrm{rp}$ & Dako & $1: 800$ & none \\
CD117 & $\mathrm{mm}$ & Dako & $1: 100$ & Steam \\
p53 & $\mathrm{mm}$ & Dako & $1: 2400$ & Steam \\
p63 & $\mathrm{mm}$ & Novocastra, Newcastle-upon-Tyne, & $1: 100$ & Steam \\
Ki67 & & United Kingdom & $1: 20$ & Steam \\
\hline
\end{tabular}

$m m$ mouse monoclonal; rp rabbit polyclonal

$37^{\circ} \mathrm{C}$. Heat induced epitope retrieval was performed, as required, by using formalin-fixed, paraffin-embedded tissue treated with a buffered citric acid solution pH 6.0 (Citra, Dako Corporation, Carpinteria, CA) and heated for $20 \mathrm{~min}$ in a steamer. Following this, the sections were allowed to cool at room temperature in a citric acid buffer solution for $45 \mathrm{~min}$ before continuing the procedure. Standard positive controls were used throughout, with serum used as the negative control. The antibody reactions were graded as absent to weak ( 0 to $1+$ ), moderate $(2+$ to $3+$ ) and strong $(4+)$ staining, and the fraction of positive cells was determined by separating them into four groups: $<10 \%$, $11-50 \%, 51-90 \%$, and $>90 \%$, especially for the proliferation markers.

A review of publications in English (MEDLINE 19662008) was performed, with all cases reported as ceruminal neoplasms included in the review. However, many cases were excluded if the lesion arose primarily in the middle ear, endolymphatic sac region, or represented a neuroendocrine adenoma (middle ear adenoma), or a primary salivary gland (parotid) tumor or extended into the ear from a tumor "centered" in the oral cavity, nasal cavity, nasopharynx, sinuses, or soft tissues of the neck were excluded $[2,8,15,19-28]$.

\section{Results}

\section{Clinical}

The patients included 6 women and 11 men (Table 4). Their ages ranged from 33 to 82 years of age, with an overall mean age at presentation of 59.5 year (median,
Table 4 Clinical and macroscopic characteristics

\begin{tabular}{|c|c|}
\hline Clinical characteristics & Ceruminous carcinoma \\
\hline \multicolumn{2}{|l|}{ Gender } \\
\hline Women & 6 \\
\hline Men & 11 \\
\hline \multicolumn{2}{|l|}{ Age (in years) } \\
\hline Range & $33-82$ \\
\hline Mean & 59.5 \\
\hline Women (mean) & 56.2 \\
\hline Men (mean) & 61.3 \\
\hline \multicolumn{2}{|l|}{ Symptom duration (in months) } \\
\hline Range & $2.5-24$ \\
\hline Mean & 8.2 \\
\hline Women (mean) & 18.0 \\
\hline Men (mean) & 6.3 \\
\hline \multicolumn{2}{|l|}{ Symptoms at presentation ${ }^{\mathrm{a}}$} \\
\hline Mass & 14 \\
\hline Hearing changes & 5 \\
\hline Drainage & 4 \\
\hline Pain & 2 \\
\hline Nerve changes (paralysis) & 3 \\
\hline \multicolumn{2}{|l|}{ Location } \\
\hline Left & 7 \\
\hline Right & 10 \\
\hline \multicolumn{2}{|l|}{ Size (in cm) } \\
\hline Range & $0.5-3.0$ \\
\hline Mean & 1.8 \\
\hline Women (mean) & 1.4 \\
\hline Men (mean) & 2.0 \\
\hline
\end{tabular}

a Patients may have presented with more than one symptom; therefore the numbers do not add up to the total number of patients 
64 years). The average age at presentation for women was younger than men, at 56.2 and 61.3 years, respectively, but there are too few cases to reach statistical significance. Patients most frequently presented with a mass lesion in the outer one-half of the external auditory canal $(n=14)$. Other symptoms included hearing changes usually conductive rather than sensorineural $(n=5)$, otitis with drainage $(n=4)$, pain $(n=2)$, and nerve changes or paralysis (facial nerve or other cranial nerve involvement; $n=3$ ). Most patients presented with more than one symptom while there were no asymptomatic patients. By definition none of the tumors were centered in the parotid gland or developed in patients who had a previous parotid gland tumor, nor in patients who had a nasopharynx primary which had involved the eustachian tube. The duration of symptoms ranged from 2.5 to 24 months, with an average of 8.2 months. On average, women (mean, 18.0 months) experienced a longer duration of symptoms than men (mean, 6.3 months), a finding without an obvious explanation. When separated by histologic type, the mean duration of symptoms was quite different: ceruminous adenocarcinoma, NOS: 5.8 months; ceruminous adenoid cystic carcinoma: 9.3 months; ceruminous mucoepidermoid carcinoma: 24 months. Given the very limited number of cases, statistical analysis could not confirm these differences.

\section{Pathologic Features}

\section{Macroscopic}

All neoplasms arose in the external auditory canal lateral to the bony-cartilaginous junction, even though there was extension into the mastoid bone, middle ear and base of the skull in two patients. Tumors, when described, were identified in the posterior-superior quadrant $(n=8)$. All tumors were unilateral and the majority affected the right side $(n=10$; Table 4$)$. The tumors were often exophytic, ranged in size from 0.5 to $3.0 \mathrm{~cm}$, with a mean size of $1.8 \mathrm{~cm}$. The tumors which arose in women were smaller (mean, $1.4 \mathrm{~cm}$ ) than their male counterparts (mean, $2.0 \mathrm{~cm}$ ), a curious finding given the inverse differences in duration of symptoms (see above). There was a slight difference in size of the tumor when separated by histologic sub-type: ceruminous adenocarcinoma, NOS: $1.7 \mathrm{~cm}$; ceruminous adenoid cystic carcinoma: $1.6 \mathrm{~cm}$; ceruminous mucoepidermoid carcinoma: $3.0 \mathrm{~cm}$. Axiomatic, the tumors which extended into other parts of the ear, were also larger (mean, $3.0 \mathrm{~cm}$ ). Curiously, tumors on the left were larger than those on the right (mean, 2.0 vs. $1.6 \mathrm{~cm}$, respectively). As a result of surgical procedures, the tumors were received by the pathologist fragmented into small pieces without an obvious surface epithelium. The tumor samples were firm and grayish white to pink. It was important to obtain an accurate location of the biopsy from the surgeon, to exclude glandular neoplasms from the parotid gland or middle ear.

\section{Microscopic}

The neoplasms do not have a true capsule and are not circumscribed, but instead tend to infiltrate into the surrounding stroma and bone (Fig. 1). Surface involvement was identified in an only six cases (Fig. 2), with surface ulceration in an additional neoplasm. The neoplasms were divided into three major groups based on specific histologic

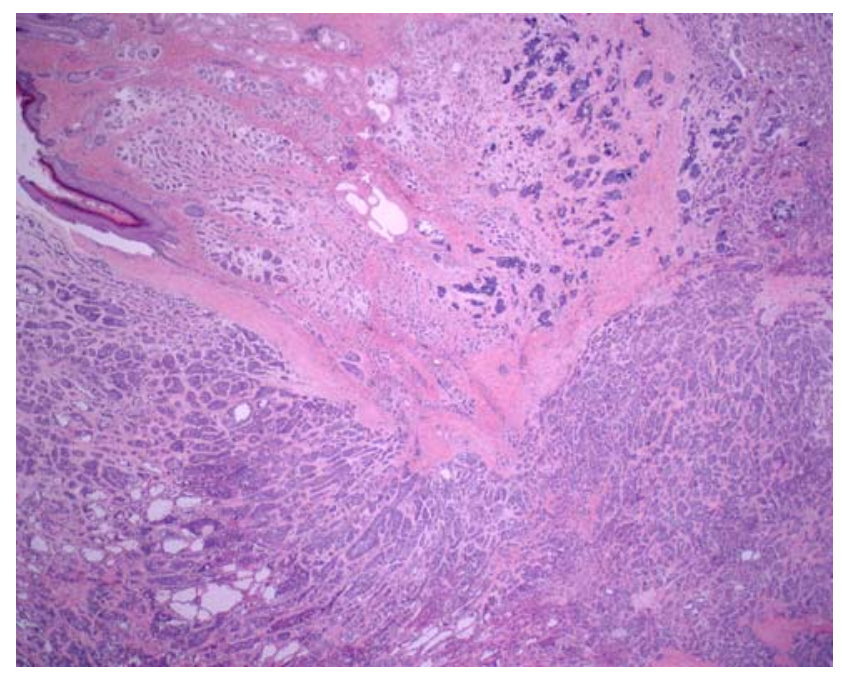

Fig. 1 Ceruminous adenoid cystic carcinoma. The surface is intact (upper left). The neoplasm is arranged in glands, nests, cribriform and solid groups infiltrating deep below the surface

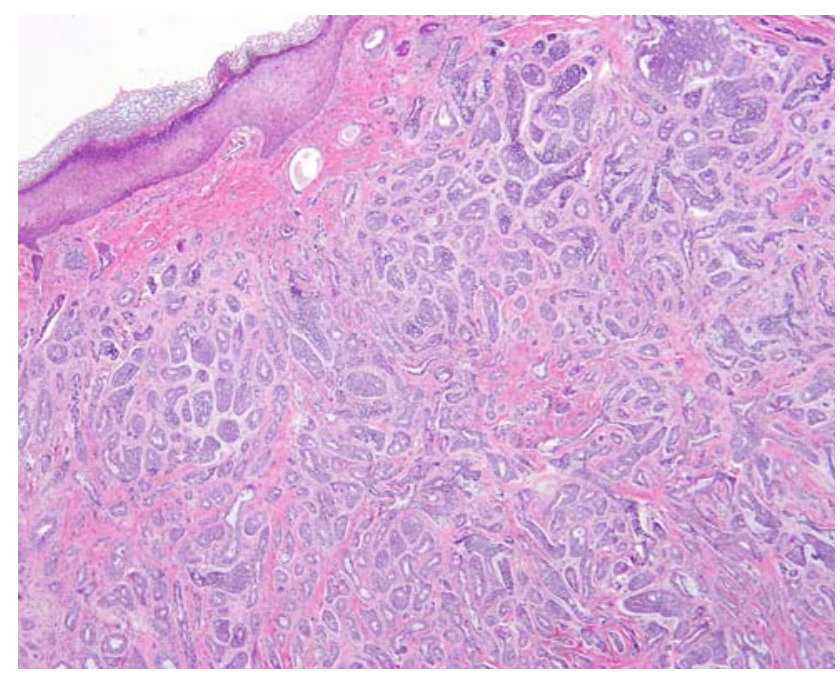

Fig. 2 Ceruminous adenocarcinoma, NOS. An intact surface epithelium is subtended by an infiltrating "biphasic" neoplastic proliferation separated by dense fibrosis 
Table 5 Microscopic features

\begin{tabular}{lc}
\hline Feature & Ceruminous carcinoma \\
\hline Growth pattern & \\
$\quad$ Glandular & 15 \\
$\quad$ Infiltrating & 12 \\
$\quad$ Solid & 8 \\
$\quad$ Cystic & 8 \\
Dual population & 15 \\
Surface involvement & 6 \\
Ulceration & 1 \\
Mitotic figures (mean per 10 HPF) & 2.9 \\
Atypical mitotic figures present & 6 \\
Pleomorphism & \\
$\quad$ Mild & 3 \\
$\quad$ Moderate & 10 \\
$\quad$ Severe & 4 \\
Cellularity & \\
$\quad$ Low & 1 \\
$\quad$ Moderate & 7 \\
High & 9 \\
Prominent nucleoli & 13 \\
Ceruminal apocrine decapitation secretion & 14 \\
Necrosis present & 2 \\
Cerumen/wax granules & 0 \\
Associated findings: & \\
$\quad$ Cholesteatoma & \\
\hline . & \\
\hline
\end{tabular}

HPF High power field

findings: ceruminous adenocarcinoma, not otherwise specified (NOS) $[n=12]$, ceruminous adenoid cystic carcinoma $[n=4]$, and ceruminous mucoepidermoid carcinoma $[n=1]$.

The ceruminous adenocarcinomas contained neoplastic cells which were arranged in a variety of different patterns within a single case as well as between cases (Table 5; Fig. 3). Whereas a glandular pattern predominated in most lesions ( $n=15$; Fig. 4), a "Swiss-cheese" or "cribriform" architecture is usually seen in ceruminous adenoid cystic carcinoma (Fig. 5). The lesional cells invaded into the surrounding stroma, a feature helpful in separating between ceruminous adenomas and carcinoma. At least focally, a dual cell population could always be identified, comprised of inner luminal epithelial cells subtended by basal/myoepithelial cells adjacent to the basement membrane (Figs. 6, 7). In the adenoid cystic carcinoma, the cells were "peg" or "carrot-shaped" with scant cytoplasm surrounding hyperchromatic nuclei (Fig. 8). When the luminal cells were identified, prominent apical caps with ceruminoustype decapitation secretion $(n=5)$ were displayed. The golden-yellow-brown pigment granules were not seen in this type of ceruminous adenocarcinoma. The tumors

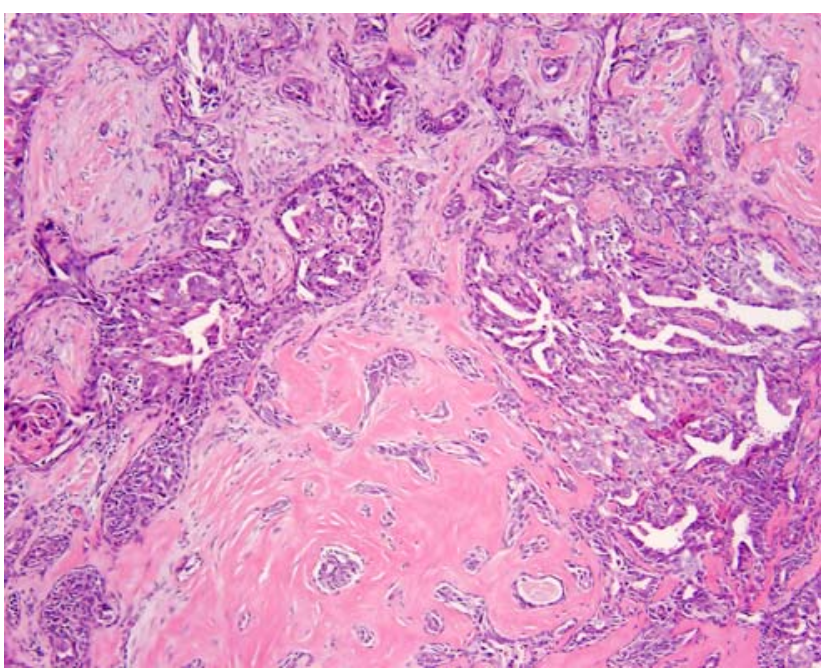

Fig. 3 Ceruminous adenocarcinoma, NOS. Glands, papillary structures, and tubules infiltrate into a heavily desmoplastic stroma. Note apoptosis and focal comedotype necrosis

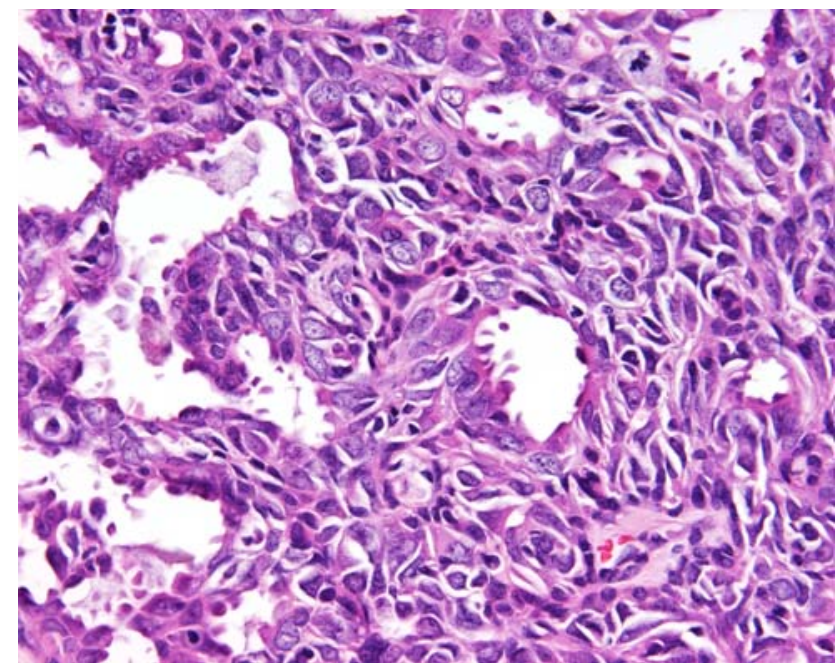

Fig. 4 Ceruminous adenocarcinoma, NOS. Hyperchromatic and moderately pleomorphic cells demonstrating a dual cell layer. The inner, more eosinophilic cells, are apocrine cells with focal decapitation secretions, while the outer layer is composed of myoepithelial cells

tended to have a moderate to high cellularity composed of cells with variably degrees of nuclear pleomorphism. Nucleoli were often prominent. Mitotic figures were usually easy to identify, with occasional atypical forms. Tumor necrosis (not degenerative change) was not observed in adenoid cystic carcinoma, but could be seen in ceruminous adenocarcinoma, NOS (Fig. 9). Inflammatory cells and areas of dense hyalinization (sclerosis) were seen. Mucoepidermoid carcinoma contained epidermoid cells, mucinproducing cells, and transitional cells, associated with focal apocrine snouts, confirming ceruminous derivation (Fig. 10). 


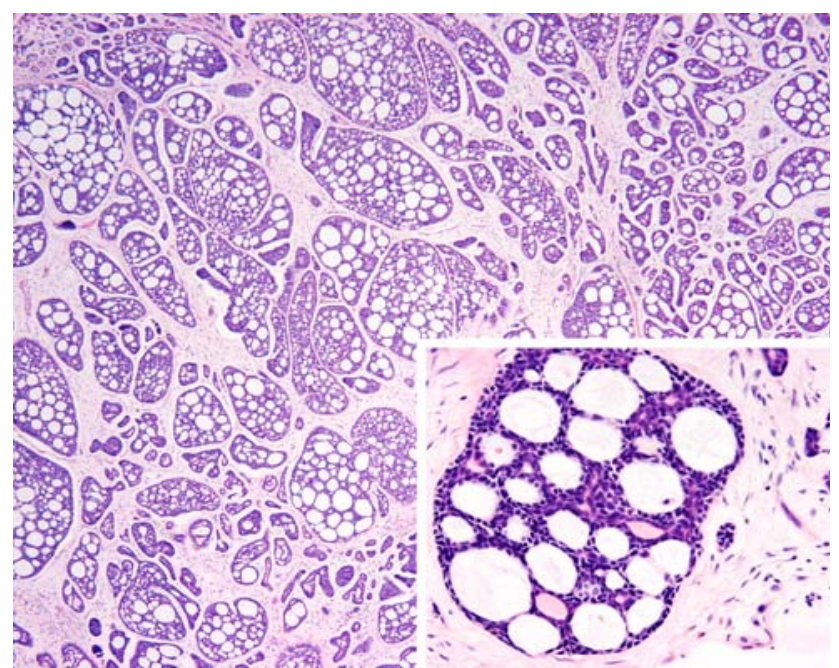

Fig. 5 Ceruminous adenoid cystic carcinoma. The overall cribriform ("Swiss-cheese") pattern is seen on both the low power and within the inset

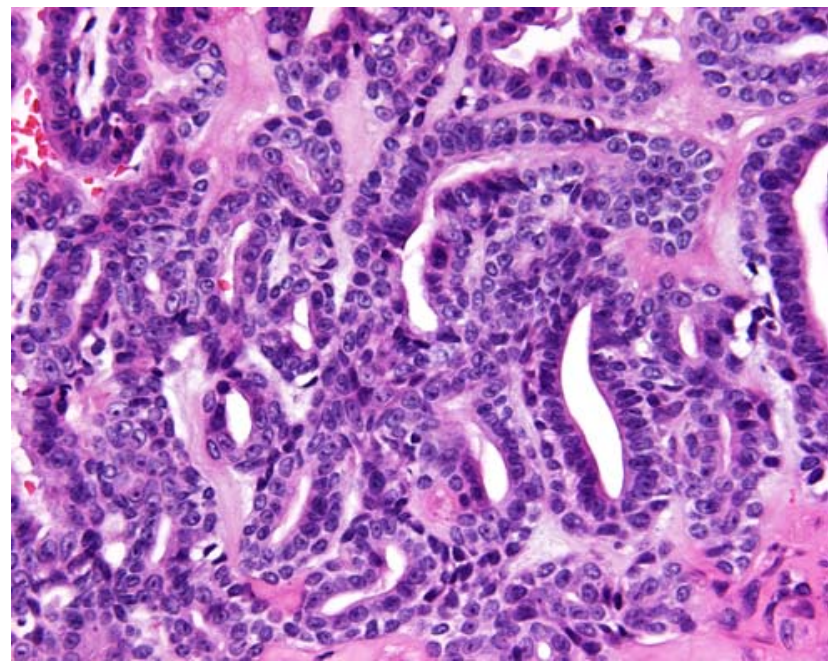

Fig. 6 Ceruminous adenocarcinoma, NOS. The neoplastic cells are atypical, demonstrating a dual cell population (inner and outer cell layers)

\section{Immunohistochemical}

All lesions tested reacted strongly and diffusely with a keratin cocktail and with epithelial membrane antigen (Table 6). Where the surface epithelium was present, it was strongly and diffusely immunoreactive for the epithelial markers analyzed, and served as an internal quality control. The dual cell population was accentuated by the immunohistochemical studies. The luminal cells were strongly immunoreactive with CK7 and with CD117 (Fig. 11). The basal-myoepithelial cells were strongly and diffusely reactive in both the nucleus and cytoplasm with S-100

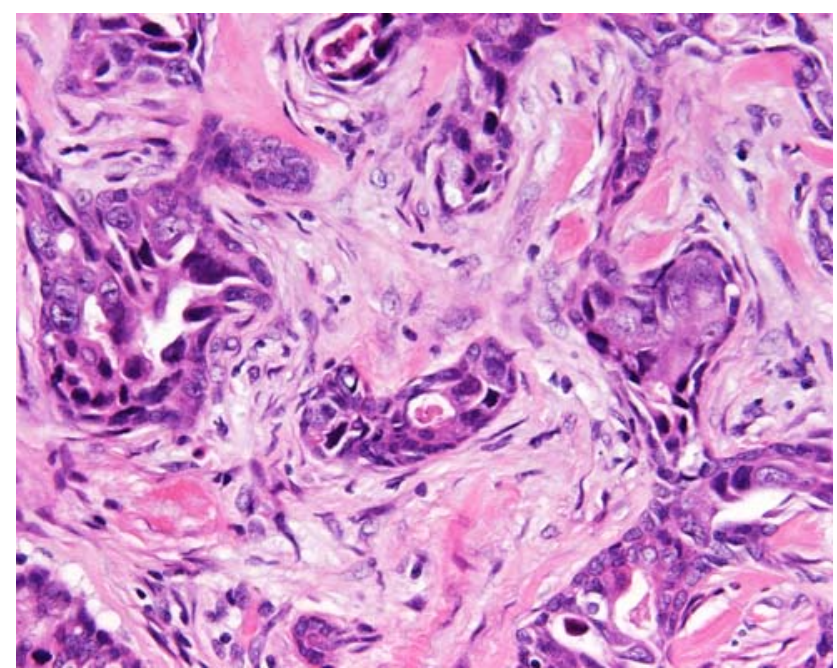

Fig. 7 Ceruminous adenocarcinoma, NOS. Irregular glands separated by desmoplastic stroma. Note the biphasic appearance with inner cells subtended by myoepithelial cells. The degree of pleomorphism is severe in this case

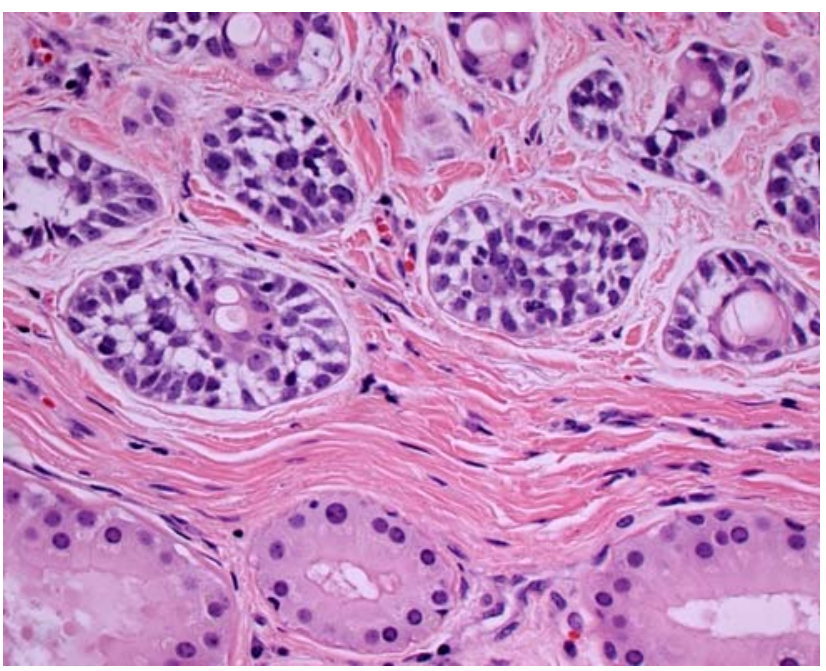

Fig. 8 Ceruminous adenoid cystic carcinoma. The lower aspect contains uninvolved ceruminous glands with small slightly yellow ceroid granules in the cytoplasm. Note the "basaloid" cells surrounding brightly eosinophilic luminal cells in the center of the tumor nests, a feature of ceruminous differentiation

protein (63\%), in the cytoplasm with CK5/6 (50\%) and in the nucleus only with p63 (38\%; Fig. 12). Thirty-seven percent of cases tested demonstrated Ki-67 immunoreactivity ranging from $2+$ to $3+$, affecting greater than $5 \%$ of the nuclei in the specimen, while the others showed $<1 \%$ reactivity. p53 was identified in $57 \%$ of cases; although immunoreactivity ranged from $1+$ to $3+$, less than $10 \%$ of the nuclei in the specimen were affected in 3 cases, while 1 case demonstrated reactivity in about $30 \%$ of nuclei. CK20 was negative in all cases tested. 


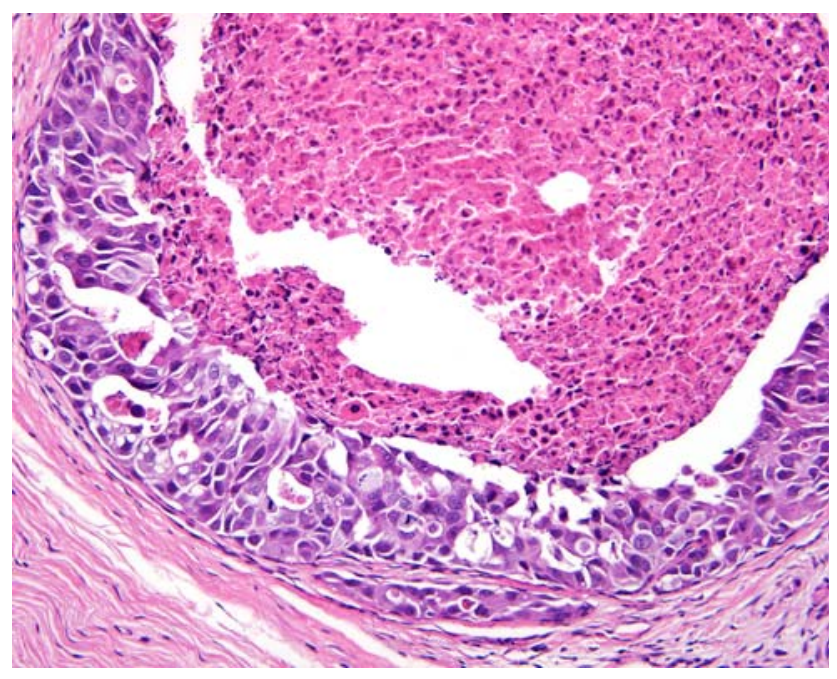

Fig. 9 Remarkably atypical epithelial cells are seen surrounding an area of central comedonecrosis, an uncommon feature in ceruminous gland adenocarcinomas

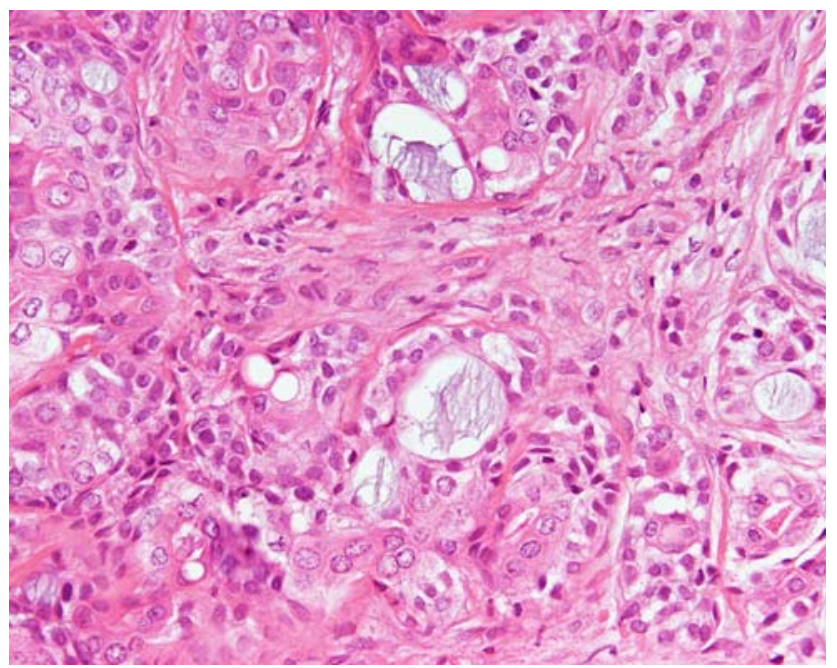

Fig. 10 Ceruminous mucoepidermoid carcinoma. Intermediate, epithelial cells and mucous cells are readily identified in this infiltrating neoplasm

\section{Treatment and Follow-up}

All patients were treated by partial or complete surgical excision; complete surgical removal of the tumor was frequently impossible as a result of the complex anatomy of the ear and temporal bone. No patients received adjuvant chemotherapy, but four patients received radiation therapy from 28 to 30 centigray. Follow-up data was obtained in all 17 patients (Table 7). There was an overall 8.9 year mean follow-up. Eleven patients were either alive $(n=8)$ or had died $(n=3)$ without evidence of disease at last follow-up, an average of 11.2 years after diagnosis. Six patients had died of disease, an average of 4.9 years after initial presentation. Of the patients who died, three had widely
Table 6 Immunohistochemical panel results

\begin{tabular}{ll}
\hline Antibody & $\begin{array}{l}\text { Number of cases } \\
\text { with positive reactions }\end{array}$ \\
\hline Cytokeratin (AE1/AE3 and LP34) & $8 / 8(100 \%)$ \\
Epithelial membrane antigen (EMA) & $8 / 8(100 \%)$ \\
CK7 (luminal only) & $6 / 8(75 \%)$ \\
CK5/6 (basal cells predominantly) & $4 / 8(50 \%)$ \\
CK20 & $0 / 8(0 \%)$ \\
S-100 protein (basal cell only) & $5 / 8(63 \%)$ \\
CD117 & $3 / 8(38 \%)$ \\
p53 & $4 / 7(57 \%)$ \\
p63 & $3 / 8(38 \%)$ \\
Ki67 & $3 / 8(>5 \%$ reactivity)
\end{tabular}

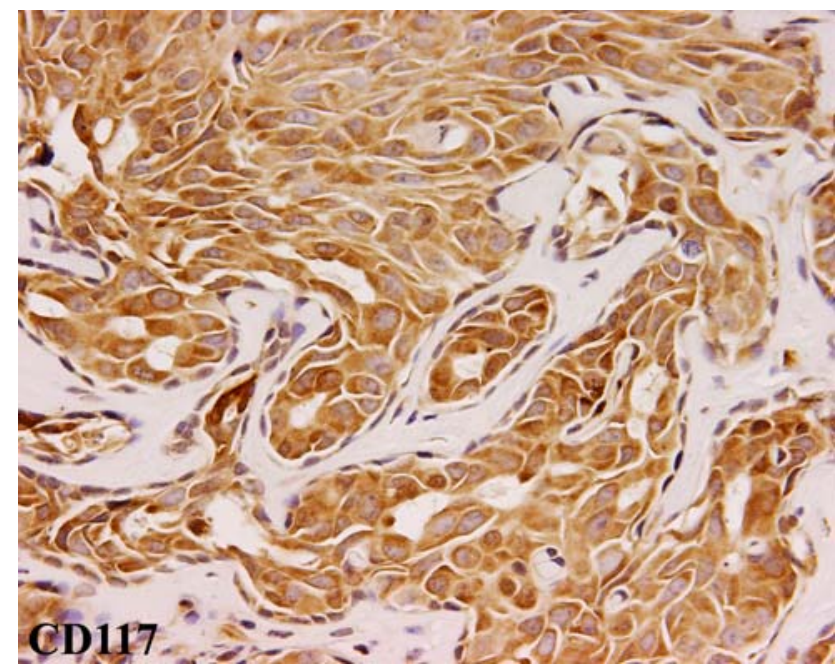

Fig. 11 Ceruminous adenocarcinoma, NOS. Note the strong reaction with CD117 in the tumor cells

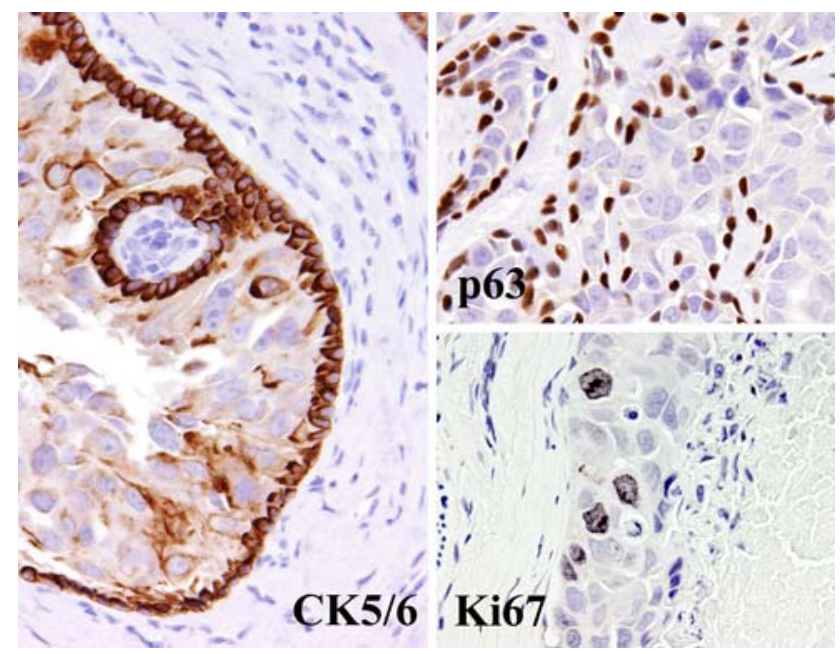

Fig. 12 Ceruminous adenocarcinoma, NOS demonstrates a "biphasic" immunoreactivity with the outer cell layer demonstrating a positive CK5/6 and p63 immunoreactivity. The Ki-67 demonstrated increased reactivity in some adenocarcinomas 
Table 7 Patient outcome for 17 ceruminous carcinomas (mean years of follow-up)

$A, N E D$ Alive, no evidence of disease; $D, N E D$ Dead, no evidence of disease; $D, D$ Dead, with disease; $n / a$ Not applicable; NOS Not otherwise specified

\begin{tabular}{lllll}
\hline & All patients & A, NED & D, NED & D, D \\
\hline All patients with follow-up & $17(8.9)$ & $8(12.0)$ & $3(8.8)$ & $6(4.9)$ \\
Follow-up range & $0.4-21.6$ & $3.4-21.6$ & $2.5-12.9$ & $0.3-11.6$ \\
Patients with recurrence & $6(8.0)$ & $1(19.2)$ & $\mathrm{n} / \mathrm{a}$ & $5(5.7)$ \\
Men & $11(8.2)$ & $3(12.5)$ & $3(8.8)$ & $5(5.2)$ \\
Women & $6(10.4)$ & $5(11.8)$ & $\mathrm{n} / \mathrm{a}$ & $1(3.1)$ \\
Tumor histology: & & & & \\
\multicolumn{1}{l}{ Adenocarcinoma, NOS } & $12(9.1)$ & $7(12.8)$ & $2(6.7)$ & $3(2.0)$ \\
$\quad$ Adenoid cystic carcinoma & $4(9.9)$ & $1(6.9)$ & $1(12.9)$ & $2(10.0)$ \\
$\quad$ Mucoepidermoid carcinoma & $1(3.1)$ & $\mathrm{n} / \mathrm{a}$ & $\mathrm{n} / \mathrm{a}$ & $1(3.1)$ \\
\hline
\end{tabular}

disseminated disease (mean survival, 6.7 years), and three had local recurrence (mean survival, 3.0 years). The local recurrence involved extension into the base of the skull or brain which resulted in the patient's death. The locally recurrent tumors were histologically identical to the primaries, without de-differentiation. None of the patients in this series developed lymph node metastases. The three patients with metastatic disease all developed locally recurrent disease first, associated with infiltration of the base of the skull, with further development of lung metastases. One of these patient's also developed liver metastases. The liver metastasis was histologically similar to the primary mucoepidermoid carcinoma. Of the patients who died of their disease, there were three with ceruminous adenocarcinoma, NOS (mean survival, 2.0 years), two with ceruminous adenoid cystic carcinoma (mean survival, 10.0 years), and one with ceruminous mucoepidermoid carcinoma (survival, 3.1 years). The four patients who received radiation therapy had an overall mean follow-up of 9.3 years; two patients died with disease (mean, 4.2 years), and two patients were alive with no evidence of disease at last follow-up (mean, 14.3 years). One of the patients who received radiation had a ceruminous mucoepidermoid carcinoma (3.1 years), while the other three had ceruminous adenocarcinoma, NOS (mean follow-up, 11.3 years). Six of the patients developed recurrences, although one patient developed "recurrence" and died with disease in 0.3 years. This patient was interpreted to have residual disease, incompletely excised at the first surgery, with extension into the skull and base of brain (ceruminous adenocarcinoma, NOS). The remaining five patients who developed recurrences were all managed with extensive local resection (including temporal bone resection), with two of these patients also undergoing adjuvant radiation therapy. The recurrences developed in three patients with ceruminous adenocarcinoma, NOS (mean survival, 8.3 years), two patients with adenoid cystic carcinoma (mean survival, 10.0 years), and one patient with mucoepidermoid carcinoma (survived, 3.1 years). The recurrences developed within a few months to 4.1 years after the primary tumor diagnosis. There is no statistically significant difference in overall survival between patients who developed a recurrence and those who did not. Further, there was no statistically significant difference in outcome between men and women, or between the different tumor types. However, while patients with ceruminous adenocarcinoma, NOS tend to have an overall shorter survival (mean, 9.1 years) than patients with adenoid cystic carcinoma (mean, 9.9 years), the number of cases was insufficient to reach statistical significance.

\section{Discussion}

The normal external ear canal is an S-shaped passage measuring about $2.5 \mathrm{~cm}$, lined by a very thin squamous mucosa covering scant fibrous stroma containing both sebaceous and modified apocrine sweat glands-ceruminal glands [29-31]. Hair follicles develop by invagination from the epidermis with sebaceous glands and ceruminous glands branching from the epithelium lining follicular root sheaths, together forming the apopilosebaceous unit [32]. The ceruminal glands are deep within the dermis, usually bordering the cartilage which is present in the outer onethird to one half of the canal. The inner bony portion of the canal does not contain ceruminal glands. The external auditory canal is bounded anteriorly by the temporomandibular joint, inferiorly by the parotid space and posteriorly by the mastoid air cells [29]. The ceruminal glands are comprised of columnar cells containing intensely eosinophilic cytoplasm, frequently displaying "apical caps," "secretory snouts," or "blebbing." These cells are surrounded by a layer of myoepithelial cells. By definition, ceruminous cells lose part of their cytoplasm during secretion, different from the holocrine sebaceous glands, which lose all of the cell as part of the secretion. Ceruminal glands are typical apocrine sweat-glands with a watery fluid secretion devoid of lipids. This fluid drains into ducts which open, along with the sebaceous gland ducts, into the hair sacs of the fine hairs in the ear canal. This fluid mixes 
with the "secretion" of the sebaceous glands to create cerumen (wax, ceroid). The luminal secretory cells contain cytoplasmic golden yellow-brown, water-insoluble lipoprotein pigment granules, similar to apocrine glands elsewhere, although these pigment granules do not become part of the secretion (Fig. 8) [8, 10, 29-31, 33]. These granules are periodic acid-Schiff (PAS) positive, Sudan black positive, and also stain with the Ziehl-Neelsen acidfast method. It is quite interesting to note that while this yellow-brown granule confirms the ceruminous nature of the benign neoplasms (ceruminous adenoma), these granules are not identified in the cytoplasm of the malignant neoplasms [30]. The immediately adjacent, uninvolved ceruminous glands will contain the pigment, helping to confirm the point of origin, and this finding can be helpful when trying to separate benign and malignant neoplasms of the ceruminous glands, especially when the biopsies are small and limited. Many ceruminous neoplasms contain both epithelium and myoepithelium, helping to confirm an origin of these tumors from ceruminous glands [10, 34, 35]. There has been a view that ectopic salivary gland within the ear canal may be the source of tumor. However, salivary gland tissue, the lining of the middle ear, and eustachian tube are derived from the expanding terminal end of the first pharyngeal pouch, different from the epithelium of the external auditory canal. Sebaceous glands in the external auditory canal may be a potential site of origin for ceruminous mucoepidermoid carcinoma, but as these glands are intimately associated with the ceruminal glands (secretions blend to create cerumen), this possibility cannot be confirmed.

\section{Nomenclature}

Reviewing the literature relevant to tumors of the ceruminous gland region is burdened with a multitude of problems. These difficulties include confusion about the terms which have been applied to ceruminous tumors, inadequate histologic descriptions, and a lack of pertinent illustrations (Table 1). Specifically, over the past few years, diagnostic terms have been applied more rigorously to tumors, allowing for the more accurate separation of tumors. The endolymphatic sac tumor [36], neuroendocrine adenoma of the middle ear [37], middle ear adenocarcinoma, and ceruminous adenoma [35] have been much more completely described and refined. Critical review of many of the earlier case reports of ceruminous neoplasms allow for a more accurate placement in different tumor categories [2, 8, 15, 19-28]. Careful review of the remaining cases, most of which are single case reports or limited case series, further narrows the number of cases available for review (see Table 2) $[4,5,10,12,14,16-18,29-32,38-66]$. Ceruminous tumors are so uncommon that only the
Table 8 Nomenclature for ceruminous (ceruminal) neoplasms of the external auditory canal

\begin{tabular}{ll}
\hline Benign neoplasm & Malignant neoplasm \\
\hline Ceruminous adenoma & Ceruminous adenocarcinoma, NOS \\
Ceruminous pleomorphic & Ceruminous adenoid cystic \\
adenoma & carcinoma \\
Ceruminous & Ceruminous mucoepidermoid \\
syringocystadenoma & carcinoma \\
papilliferum & \\
\hline
\end{tabular}

NOS Not otherwise specified

experience which can be achieved from a referral center or academic medical center would allow for an improvement in the understanding of this neoplastic category. Advancement in understanding ceruminous neoplasms can be made by the strict application of more uniform nomenclature. While it is not the foremost purpose of this study to resolve taxonomic issues nor to specifically correct nosological preferences, a considerable part of the confusion attending this group of neoplasms can be attributed to the persistent use of inappropriate terms. Therefore, comment must be made to assist the pathologist and clinician alike in implementing uniform nomenclature (Table 8).

Malignancies of the ceruminous glands of the external auditory canal constitute a rather uncommon group of tumors, representing $<0.0001 \%$ of all surgical cases studied [4]. The generic "ceruminoma" and "cylindroma" has been used to encompass both histologically benign and malignant glandular tumors of the external auditory canal, thereby providing the clinician and surgeon with little value and no guidance as to management and follow-up. The continued use of these names, particularly ceruminoma and cylindroma, is strongly discouraged and are viewed as "defunct" $[4,10,17,19,31,34,35,67]$. The tumors are correctly classified under benign and malignant categories. The benign category encompasses ceruminous adenoma, ceruminous pleomorphic adenoma and ceruminous syringocystadenoma papilliferum. The malignant category includes ceruminous adenocarcinoma, not otherwise specified (NOS), ceruminous adenoid cystic carcinoma and ceruminous mucoepidermoid carcinoma, each defined by the unique attributes of the underlying malignancy. With this terminology in mind, a comparison of the cases reported in the literature to the cases in this study is carried out.

\section{Clinical}

All of the neoplasms studied in our series and in those of the literature developed exclusively in adults, with this study's age range of 33-82 years, encompassed by the 
patients reported in the literature of 21-92 years at presentation [4, 17, 18, 31]. Malignant neoplasms tend to develop at a younger age at initial presentation than benign neoplasms, a difference of approximately one decade, although it is difficult to achieve statistical significance with this type of meta analysis $[4,18,35]$. There was no statistical difference in the age at presentation between men and women, either for our study or for the average age at presentation for those patients reported in the literature. There is a slight gender predilection for female patients when the patients in this series are combined with those in the literature ( $\mathrm{F}: \mathrm{M}=5: 4)$. The greater number of men in this clinical series may be biased by cases from military and Veterans Administration hospitals which tend to be male dominant. Gender did not seem to influence tumor type, as the most common tumor type identified in either gender was ceruminous adenoid cystic carcinoma (women, $74 \%$; men, 65\%). However, in this clinical series, ceruminous adenocarcinoma, NOS was the most common tumor type, perhaps due to a selection bias of a consultation service, where ceruminous adenocarcinoma, NOS may be more difficult to diagnose than a ceruminous adenoid cystic carcinoma.

The most common symptoms reported in the literature and in our patients included pain (otalgia), mass, and hearing changes (hearing loss, deafness, tinnitus, popping). Other symptoms included drainage, discharge, infection, bleeding, paralysis, paresthesias, weakness, syncope, dizziness, equilibrium changes, headaches, swelling, drum perforation, and visual changes $[4,10,17,18,29,53]$. No patients in our series were asymptomatic, but asymptomatic patients have been reported [50]. Symptoms did not specifically correlate with a distinct tumor type, with duration of symptoms, nor with patient outcome. Some in the literature have suggested that patients with a long symptom duration tend to have a worse outcome [68], but we were unable to confirm this result nor tease this information from the reported cases. In this clinical series, the duration of symptoms ranges from 2.5 months to 2 years, with the mean being 8.2 months. This average is significantly shorter than the mean reported in the literature (51.6 months). The potential reasons for this remarkable discrepancy are: (1) cases reported in the literature do not give length of symptom duration (29 cases have no information); (2) there tends to be a reporting bias towards the unusual or uncommon, such as with patients who have had symptoms for greater than 10 years [4, 29, 31, 64]; (3) the median in the literature is 27.5 months, a much more realistic symptom duration than the mean 51.6 month. Our analysis shows an interesting breakdown along gender. Women presented having symptoms an average of one year longer (18 months) in duration then men (6.3 months), but this may just be due to the limited number of cases, as the difference between men and women reported in the literature is the exact opposite (men: 64.4 months; women: 41.7 months).

\section{Pathology Features}

On physical exam, the masses ranged in size from 0.5 to $3.0 \mathrm{~cm}$, identical to those the cases reported in the literature. The mean size of $1.8 \mathrm{~cm}$ is slightly larger than those reported in the literature (mean, $1.4 \mathrm{~cm}$ ). It is important to note, small biopsies may lead to incorrect interpretation. Therefore, caution is advised when only isolated fragments of tumor are included in the sample. Interestingly, in this clinical study even though the female patients tended to suffer with symptoms for a longer duration, their tumors were on average were over a half a centimeter smaller than their male counterparts (females: mean, $1.4 \mathrm{~cm}$; males: mean, $2.0 \mathrm{~cm}$ ). The female patient's mean tumor size reported in the literature is quite similar at $1.5 \mathrm{~cm}$, although the mean size reported for males was smaller than our patients, at $1.2 \mathrm{~cm}$. We do not have an explanation for the size differences. Although the tumors in this study affected the right side $(n=10)$ more frequently than the left $(n=7)$, there was no statistically significant difference, a finding similar to the patients reported in the literature (left $=39$; right $=33$ ).

Based on the well established criteria for adenoid cystic carcinoma and mucoepidermoid carcinoma in other anatomic sites, the tumors in this series were separated into ceruminous adenocarcinoma, NOS $(n=12)$, ceruminous adenoid cystic carcinoma $(n=4)$, and ceruminous mucoepidermoid carcinoma $(n=1)$. Axiomatic but still important, these tumors arose primarily in the external auditory canal without any direct continuity with the adjacent salivary gland; parotid gland specifically. It is well known that salivary gland primaries may invade along nerves and be identified synchronously or metachronously in the external auditory canal, sometimes many years after the primary parotid gland tumor was removed [4]. Further, there may have been extension into the middle ear via erosion of the tympanic membrane, but no tumors were centered within the middle ear and/or eustachian tube. The latter would be considered as a separate group of neoplasms and are not considered ceruminous primaries. As previously stated, the larger proportion of ceruminous adenocarcinoma, NOS cases may reflect the bias of a consulting service. It could be argued that ceruminous adenocarcinoma, NOS may be more difficult to diagnosis than either mucoepidermoid carcinoma or adenoid cystic carcinoma, and therefore we may see more of the former. Overlap between histologic categories is inevitable, but emphasis is given to the dominant pattern. Therefore, while we identified some adenocarcinomas that had focal features of 
adenoid cystic carcinoma, an insufficient number of features were present to warrant this diagnosis.

A peculiar finding is an overall greater number of malignant tumors of ceruminous glands than benign tumors; it is uncertain whether this may be in part of a reporting bias [4, 11, 17, 18, 29, 31, 34, 35]. If limited to the cases at the Armed Forces Institute of Pathology, malignant tumors were not as common as benign tumorsbut this may be due to a selection bias of cases [35]. Malignant-appearing cases are more likely to be sent for consultation, with a change in the diagnosis to a benign lesion altering the number of reported cases. This inference requires further evaluation to draw a definitive conclusion.

Irrespective of the tumor type, all were infiltrative neoplasms, without a capsule, showing extension into the native ceruminous glands, adipose tissue and even temporal bone. Infiltration is a helpful feature when trying to separate benign from malignant ceruminous neoplasms, although benign tumors tend to have a hyalinized fibrosis which creates a "pseudoinfiltrative" pattern [35, 69]. Many times the samples are small and fragmented. Therefore, while infiltration can be helpful, it is not as useful in an individual case as suggested by the findings in this series and the literature. Interestingly, perineural invasion and lymph-vascular invasion is difficult to detect [31]. When present, however, it helps to define the malignant nature of the tumor.

Histologically, the ceruminous glands lie "deep" in the dermis in propinquity to cartilage, not at the surface [29]. However, ceruminous glands disgorge their secretions via ducts onto the surface. The skin in the outer two-thirds of the ear canal is only about $0.2 \mathrm{~mm}$ thick, suggesting that even though "deep" in the dermis, they are still relatively close to the surface [29]. Therefore, it is not uncommon to find ceruminous neoplasms extending to the surface epithelium, as noted in six of our cases. This finding does not support a surface origin, however, only a surface involvement. Moreover, Pagetoid spread within the epidermis was not identified. Ulceration was seen in only a single case in this clinical series, and shown in a few of the reported cases in the literature. Then again, surface ulceration can be seen in benign tumors, making ulceration alone less specific for malignancy. Further, the ear canal is a small, confined space, frequently subjected to trauma (cotton tipped applicators, digital exam), which may result in ulceration unrelated to the underlying disease.

Ceruminous adenocarcinomas, NOS are similar to adenocarcinomas of any anatomic site, except that ceruminous glands are identified adjacent to or within the tumor. Tumors show an increased cellularity, with cells demonstrating anisocytosis and pleomorphism. The cells generally resemble secretory cells, although demonstrating back-to-back gland formation and irregular glandular configurations [31]. Papillary structures can be seen, although they are seldom dominant [45]. Nucleoli are easily identified in approximately $75 \%$ of cases. Prominent nucleoli may be a helpful feature, since benign neoplasms tend not to have prominent nucleoli [35]. Decapitation secretions or prominent apical caps were seen in over $80 \%$ of cases, even when the tumors were poorly differentiated, another support for ceruminous origin. This finding is different from other authors who failed to identify apocrine blebs in poorly differentiated tumors [18]. The secretions were frequently admixed with cellular debris within the gland lumen. The characteristic golden-yellow-brown pigment (cerumen granules) within the cytoplasm of benign ceruminous glands and benign ceruminous neoplasms, is not identified in malignant tumors [30]. This absence (after careful examination) may help in separating benign from malignant ceruminous tumors. Myoepithelial cells, the basal layer of normal ceruminous glands, were easily identified in most tumors, although much more easily accentuated with immunohistochemical myoepithelial and basal markers (S-100 protein, p63). These cells often show a cleared cytoplasm, creating a "light" cell immediately adjacent to the "dark" cell of the ductal or luminal cell.

Mitotic figures are usually easy to find although the overall mean was 2.9 figures per 10 high power fields. Some of the tumors had no mitotic figures. Therefore, increased mitotic figures may assist in the diagnosis of malignancy, but a lack of mitotic figures does not exclude a caricnoma [35]. In fact, ceruminous adenoid cystic carcinomas generally lack mitoses, and overall, this is the most common tumor type in the meta analysis. Atypical mitotic figures are not identified in benign tumors and were present in $35 \%$ of cases in this series. Hence, atypical mitotic figures may aid in making a malignant diagnosis, but their absence does not rule out carcinoma.

Ceruminous adenocarcinoma, NOS infrequently contained tumor necrosis $(n=2)$, but when present, was considered diagnostic of carcinoma. Likewise, perineural invasion, when present $(n=1)$ was also considered diagnostic of carcinoma. Perineural invasion was only identified in ceruminous adenocarcinoma, NOS, a curious finding given the known proclivity for perineural invasion in adenoid cystic carcinomas. This is different from the frequently reported finding of perineural invasion in ceruminous adenoid cystic carcinomas [4, 10, 14, 17, 68]. These authors identified an increased risk of recurrence when perineural invasion was identified. However, parotid gland tumor extension (versus primary) cases were included, making this conclusion suspect.

Glandular differentiation was present in some form or another in all tumors studied. Solid and cystic patterns were seen about equally. Dual cell differentiation, one of the key features of ceruminous gland neoplasms, was found 
in all but one of the tumors studied. The tumor that did not show a dual cell layering was the ceruminous mucoepidermoid carcinoma. Dual cell differentiation refers primarily to the inner cuboidal and outer basal-myoepithelial type cell, a finding seen in ceruminous glands. Adenoid cystic carcinoma also shows this biphasic appearance, but the decapitation secretions within the small glands or within the tumor proper help to confirm the dual differentiation.

Adenoid cystic carcinoma is the most commonly reported primary ceruminous gland malignancy, by a $2: 1$ ratio (when the current cases are added to those reported in the literature) $[4,10,14,17,29,53]$. Ceruminous adenoid cystic carcinomas show morphologic diversity, but cytologic uniformity. Similar to their salivary gland counterparts, ceruminous adenoid cystic carcinomas show cribriform, tubular and solid patterns, although the former two predominate and are usually intermingled in a jigsaw puzzle type configuration. The low power sieve-like, perforated, or Swiss cheese-like pattern is easily recognized, and are probably the most useful initial feature in ceruminous tumor separation, as this pattern is not identified in ceruminous adenocarcinoma, NOS nor in mucoepidermoid carcinoma. The cylindrical, pseudocyst-like structures contain abundant, brightly eosinophilic connective tissue stroma and reduplicated basement membrane-lamina material which surrounds the epithelial cells, and since it is part of the stroma, is contiguous with it and meanders throughout the background in a nearly continuous stream. These structures are different from the isolated, true glandular lumens which are lined by cuboidal ductal cells. These small ductal areas are easy to miss in the overwhelmingly predominant basaloid cell proliferation, but identification allows for accurate classification. The basaloid-myoepithelial type cells are usually small with a high nuclear to cytoplasmic ratio, indistinct cell borders, and a nearly syncytial appearance. The nuclei are frequently angular to "peg-shaped," containing homogenous, darkly basophilic chromatin. Nucleoli are usually inconspicuous. The cytoplasm is lightly eosinophilic to clear, the latter more prominent in myoepithelial-type cells. Mitotic figures are difficult to identify and necrosis is usually absent. The appearance of decapitation-type apocrine snouts on some of the luminal cells and the bilayered, eosinophilic neoplastic cells helps to confirm a ceruminous origin for the neoplasm.

Ceruminous mucoepidermoid carcinoma is the most uncommon tumor type affecting the external auditory canal. By definition, this tumor has mucous, epidermoid, and transitional or intermediate cells, blended together, although the intermediate cells tend to dominate. Cysts or dilated ducts are usually present somewhere within the tumor, frequently filled with mucinous material. The epidermoid cells have ample to abundant eosinophilic to clear cytoplasm, creating a polygonal appearance. Dyskeratosis, keratin pearl formation, and intercellular bridges are usually absent in this tumor. The intermediate cells tend to have less cytoplasm than epidermoid cells, with a slightly higher nuclear to cytoplasmic ratio and less polygonal appearance. The nuclear chromatin is granular to condensed, but not as condensed as in epidermoid cells. Large, goblet shaped mucocytes contain abundant clear to foamy cytoplasm which compress or indent the nucleus, creating a signet-ring type appearance. These cells are scattered throughout the neoplasm, occasionally arranged in sheets or linear groups, and most commonly found lining cystic or duct-like spaces. These cells can be highlighted with alcian blue or mucicarmine stains. Interestingly, a clear cell morphology is not the dominant finding in ceruminous mucoepidermoid carcinomas. Background fibrosis is a minor component, along with scattered inflammatory cells.

One case was associated with a cholesteatoma. While these two separate entities are perhaps unrelated, the symptoms of the cholesteatoma may have brought attention to the malignant ceruminous gland neoplasm earlier. It is also possible, however, that the reverse is true. Cholesteatoma is not discriminating, also documented in benign ceruminous adenomas [35].

Immunohistochemistry may help to highlight the biphasic appearance of ceruminous neoplasms, with luminal ductal and abluminal myoepithelial cells in both ceruminous adenocarcinoma, NOS and ceruminous adenoid cystic carcinoma. First, all cases reacted with pankeratin. The CK7 was notable for selective reactivity in the glandular luminal cells in $75 \%$ of the cases. The basal cell layer, composed of myoepithelial cells, was reactive to $\mathrm{S}-100$ in $63 \%$ of the cases and p63 in all cases tested. CD117 was reactive in neoplastic cell in $38 \%$ of the cases. Ki67 was reactive at a rate of approximately $5 \%$ in 3 out of the 8 cases that were analyzed. This indicates a modest proliferation rate. These three tumors, however, were also some of the larger tumors (average size of $2.1 \mathrm{~cm}$ ) upon presentation. Therefore, while immunohistochemistry aids in highlighting the individual components of the neoplasm, but it does not seem to aid in the diagnosis of ceruminous malignancies based on currently available antibodies studied.

\section{Treatment and Outcome}

Follow-up was available in all of the patients in this clinical series. The overall prognosis is good, with an average follow-up of 8.9 years for all patients. The patients who died from their disease, had a mean time to death of 4.9 years from the time of initial presentation. However, 
while $25 \%$ of patients with ceruminous adenocarcinoma, NOS died of disease a mean of 2.0 years after presentation, $50 \%$ of patients with ceruminous adenoid cystic carcinoma died of disease a mean of 10 years after initial presentation. These findings are quite similar to the much longer survival periods reported for patients with ceruminous adenoid cystic carcinoma (mean, 8.3 years) than for ceruminous adenocarcinoma, NOS (mean, 4.7 years). However, most patients with adenoid cystic carcinoma had recurrences develop, both in this series and in the patients reported in the literature $[4,10,18,34,68,70]$. If a recurrence developed, there seems to be a much greater chance of dying from disease $(83 \%)$ versus patients who did not develop a recurrence $(9 \%)[4,68]$. Analysis of the cases in the literature also suggests there is a longer overall survival when a recurrence develops (mean, 8.5 years) versus no recurrence (mean, 4.6 years). However, this is probably related specifically to tumor type (ceruminous adenoid cystic carcinoma), which tends to develop recurrences later in the course of the disease, thereby resulting in a prolonged survival. In fact, it is not uncommon to develop metastatic foci in the lung many years after the primary tumor was identified [50]. Therefore, an initial extensive, widest practical and meticulous excision, with close clinical follow-up, especially in patients with adenoid cystic carcinoma, may help to delay death from recurrent disease or decrease the chance of recurrence. Surgeons may be reluctant to perform "radical" surgery for tumors which appear small, but given the very high tendency for local recurrence and metastatic disease, this effort is warranted and required. In fact, extended mastoidectomy, involved dura, and total parotidectomy including mandibular condyle may be required for ceruminous adenoid cystic carcinoma to adequately control local disease.

Surgical margin positivity at initial surgery, bone extension, perineural invasion and local recurrence seem to be important prognostic factors for cases in the literature $[4,10,18,34,68,70]$, but a number of these factors could not be independently assessed in this study. However, patients who had more aggressive surgical removal at or immediately after initial presentation were less likely to have recurrences, although independence from tumor histology could not be determined. Along this same line, other authors have included cases with parotid gland involvement in their studies of primary ceruminous gland neoplasms $[4,10,14,17,18,29,31,43,53,71,72]$. When follow-up was performed, patients with parotid gland involvement had $>90 \%$ recurrence rates and often died from their disease, as perhaps would be expected from tumors which arose in the parotid gland and extended into the bone and soft tissue of the external auditory canal.

Interestingly, when tumor type was stratified against outcome, there was no statistically significant difference in patient outcome: ceruminous adenoid cystic carcinoma: $30.4 \%$ die of disease; ceruminous adenocarcinoma, NOS: $35 \%$ die of disease; mucoepidermoid carcinoma: $50 \%$ die of disease (but with only 4 cases reported, statistical significant cannot be determined). Therefore, while there is a longer overall survival for patients with ceruminous adenoid cystic carcinoma (mean, 8.3 years) versus ceruminous adenocarcinoma, NOS (mean, 4.7 years), a similar percentage of patients die from disease in each category. However, with improved surgical techniques, perhaps additional surgery can help to secure a longer survival even though it may not change the ultimate outcome. There is no statistically significant difference between males and females, independent of tumor type: females: mean 7.6 years; males: mean, 6.1 years. Likewise, a similar percent of men and women died from their tumors (females: $30.6 \%$; males $31.3 \%$ ), although in this study a greater number of men died of their disease $(45 \%)$ versus women (17\%). This result may be due to consultation bias rather than a true finding, as the large number of cases in the literature suggest. Similarly, overall, a greater number of women seem to develop metastatic disease versus men: $40 \%$ versus $25 \%$; but these numbers were reversed in this clinical study: $15 \%$ versus $40 \%$. This may suggest, however, that tumor histologic type may be more of a factor in prognosis than gender, as our series had more men with adenoid cystic carcinoma than women, and the same is true for the literature: $74 \%$ of reported cases in women were adenoid cystic carcinoma versus $65 \%$ for men.

It seems that radiation treatment does not necessarily change the ultimate outcome of patients, but may provide for a longer overall survival. In this clinical study, $50 \%$ of patients treated by radiation died of disease (mean, 4.2 years) and $50 \%$ showed no evidence of residual disease (mean, 14.3 years). Patients reported in the literature reflect similar findings: overall, 43 patients did not receive radiation (mean overall survival, 5.9 years) while 29 patients received radiation (mean overall survival, 5.7 years). Specifically, of the patients treated with radiation: $37.9 \%$ died of disease (mean, 5.0 years) versus $48.2 \%$ with no evidence of disease (mean, 4.5 years). Radiation therapy is used more frequently in ceruminous adenocarcinoma, NOS cases than in ceruminous adenoid cystic carcinoma. Therefore, radiation probably has a role in palliation or applied at the time recurrence develops, but not necessarily at the time of initial diagnosis, except perhaps for the ceruminous adenocarcinoma, NOS group [4, 5, 10, 29, 70, 73].

Adenoid cystic carcinoma has a deceivingly favorable early prognosis, but many patients will eventually succumb to the disease. In these patients, the average period from the onset of symptoms to death is over 9 years. Therefore, it is imperative that all ceruminous malignancies be followed for many years after their initial presentation. Distant 
metastases to the lung, kidney, cervical lymph nodes, and bones have been reported, and metastases tend to maintain their primary histological identity $[4,10,14,17,29,50$, 53]. Interestingly, we did not detect any lymph node metastases in this clinical series, and it is only rarely reported, suggesting that local recurrence and/or distant metastasis is more likely than lymph node metastases. Review of the literature shows that mucoepidermoid carcinoma has a poor outcome (mean follow-up, 1.5 years), with 3 of 5 patients dead of disease, and follow-up limited to 2.2 years in the remaining two patients $[17,39,54,62]$.

Staging was not applied to these tumors, as we were not the primary treatment facility. We did not have access to radiographic studies or full operative reports to be able to determine extent of soft tissue or bone involvement and whether there was facial paralysis at presentation. There is a proposed staging for external auditory canal squamous cell carcinoma based on clinical and computed tomography findings by authors from the University of Pittsburgh [74]. While there may be some overlap, this staging is based on extent of invasion (limited to the epidermis, $<0.5 \mathrm{~cm}$ soft tissue invasion, $>0.5 \mathrm{~cm}$ soft tissue invasion, bone invasion), features which cannot be employed in ceruminous neoplasms, which by definition are arising from dermal glands, eliminating pT1 through $\mathrm{T} 3$ as potential categories.

\section{Differential Diagnosis}

Axiomatic, clinical and radiographic exclusion of a salivary gland origin (parotid gland) must be accomplished in order to produce appropriate management. Pathological diagnosis rests on the adequacy of the initial biopsy. If the biopsy is too limited, a definitive diagnosis cannot be reliably generated. The differential diagnosis includes pleomorphic adenoma (benign mixed tumor), middle ear adenoma, and low-grade adenocarcinoma of the middle ear. The dual cell population of a pleomorphic adenoma (whether of the ceruminous glands or from the parotid gland) may cause difficulty in achieving a correct diagnosis of a ceruminous gland adenoma. However, decapitation secretions are not identified and the background stroma is myxoid-chondroid rather than fibrotic [35]. A neuroendocrine adenoma of the middle ear (middle ear adenoma) also has a dual cell population, but demonstrates a finely stippled nuclear chromatin distribution and lacks decapitation secretions. Further, the immunohistochemical profile of chromogranin and human pancreatic polypeptide is unique [75]. Cellular pleomorphism can be seen in ceruminous adenoma and middle ear adenocarcinomas can be quite cytologically bland. However, true middle ear adenocarcinomas are very uncommon, and will frequently demonstrate definitive invasion of bone, cartilage, vascular channels or perineural spaces by the tumor cells. These tumors arise within the middle ear mucosa and show tympanic membrane destruction or erosion, as well as extension down the eustachian tube. Sometimes separation may require radiographic and clinical correlation.

Ceruminous adenoid cystic carcinoma may occasionally be mistaken for a primary skin tumor, specifically basal cell carcinoma. The histologic appearance on small biopsies may be identical. Therefore, it is important to consider whether the tumor is "involving" the epidermis versus "arising" from it. In some cases, excision may be the only way to make this separation accurately.

\section{Summary}

Ceruminous carcinomas are rare malignancies usually presenting with a mass or pain in the outer ear canal of middle aged patients. Tumors are large for the anatomic site. They demonstrate an infiltrative pattern with moderate to severe nuclear pleomorphism, increased mitotic figures and rarely necrosis. The tumor are classified as ceruminous adenocarcinoma, NOS, ceruminous adenoid cystic carcinoma and ceruminous mucoepidermoid carcinoma. Diagnostic difficulties are frequently encountered by the pathologist, especially when the samples are small. Prognosis may be difficult to predict, but complete surgical excision coupled with radiation yields the best long-term prognosis. Ceruminous adenoid cystic carcinoma has a prolonged course, with metastatic disease after recurrences in approximately $50 \%$ of patients, but many years after the initial tumor's excision.

Acknowledgments The opinions or assertions contained herein are the private views of the authors and are not to be construed as official or as reflecting the views of the Department of Navy.

Open Access This article is distributed under the terms of the Creative Commons Attribution Noncommercial License which permits any noncommercial use, distribution, and reproduction in any medium, provided the original author(s) and source are credited.

\section{References}

1. Moisan PG, Watson GL. Ceruminous gland tumors in dogs and cats: a review of 124 cases. J Am Anim Hosp Assoc. 1996;32:449-53.

2. Michel RG, Woodard BH, Shelburne JD, et al. Ceruminous gland adenocarcinoma: a light and electron microscopic study. Cancer. 1978;41:545-53. doi:10.1002/1097-0142(197802)41:2<545::AIDCNCR2820410222>3.0.CO;2-W

3. Batsakis JG, Hardy GC, Hishiyama RH. Ceruminous gland tumors. Arch Otolaryngol. 1967;86:66-9.

4. Perzin KH, Gullane P, Conley J. Adenoid cystic carcinoma involving the external auditory canal. A clinicopathologic study of 16 cases. Cancer. 1982;50:2873-83. doi:10.1002/1097-0142 (19821215)50:12<2873::AID-CNCR2820501230>3.0.CO;2-R. 
5. Arato J, Michel RP, Baxter JD. Ceruminoma. J Otolaryngol. 1980;9:482-6.

6. Bignardi L, Grandi E, Merlo R, et al. Functional surgery of ceruminoma of the external and/or middle ear. Rev Laryngol Otol Rhinol (Bord). 1993;114:49-52.

7. Gupta KR, Kakar PK, Saharia PS. Ceruminoma of the external ear. J Laryngol Otol. 1970;84:743-5.

8. Johnstone JM, Lennox B, Watson AJ. Five cases of hidroadenoma of the external auditory meatus: so-called ceruminoma. J Path Bact. 1957;73:421-7. doi:10.1002/path.1700730212.

9. Juby B. Tumors of the ceruminous glands: so-called ceruminoma. J Laryngol. 1965;71:832-7.

10. Mills RG, Douglas-Jones T, Williams RG. 'Ceruminoma'-a defunct diagnosis. J Laryngol Otol. 1995;109:180-8. doi:10.1017/ S0022215100129652.

11. Moss R, Labay G, Mehta N. Ceruminoma revisited. Am J Otol. 1987;8:485-8.

12. Neldner KH. Ceruminoma. Arch Dermatol. 1968;98:344-8. doi:10.1001/archderm.98.4.344.

13. O'Neill PB, Parker RA. Sweat gland tumors ('ceruminomata') of the external auditory meatus. J Laryngol. 1957;71:824-31.

14. Ramadass T, Satuanarayana C. Ceruminoma of external ear. A clinico-pathological study of three cases. J Laryngol Otol. 1973;87:1201-10. doi:10.1017/S0022215100078178.

15. Saito R, Kodaki K, Shiobara R, et al. Ceruminoma with intracranial invasion-case report. Neurol Med Chir (Tokyo). 1990;30:1034-7. doi:10.2176/nmc.30.1034.

16. Turner HA, Carter H, Neptune WB. Pulmonary metastases from ceruminous adenocarcinoma (cylindroma) of external auditory canal. Cancer. 1971;28:775-80. doi:10.1002/1097-0142(197109) 28:3<775::AID-CNCR2820280336>3.0.CO;2-3.

17. Pulec JL. Glandular tumors of the external auditory canal. Laryngoscope. 1977;87:1601-12. doi:10.1288/00005537-19771000000001 .

18. Dehner LP, Chen KT. Primary tumors of the external and middle ear. Benign and malignant glandular neoplasms. Arch Otolaryngol. 1980;106:13-9.

19. Hageman ME, Becker AE. Intracranial invasion of a ceruminous gland tumor. A follow-up of 12 years. Arch Otolaryngol. 1974;100:395-7.

20. Harrison K, Cronin J, Greenwood N. Ceruminous adenocarcinoma arising in the middle ear. J Laryngol Otol. 1974;88:363-8. doi:10.1017/S0022215100078798.

21. Dilenge D, Nutik S, Poliquin J, et al. Ceruminous tumor of the jugular foramen. J Can Assoc Radiol. 1977;28:287-90.

22. Cilluffo JM, Harner SG, Miller RH. Intracranial ceruminous gland adenocarcinoma. J Neurosurg. 1981;55:952-6.

23. Schenk P, Handisurya A, Steurer M. Ultrastructural morphology of a middle ear ceruminoma. ORL J Otorhinolaryngol Relat Spec. 2002;64:358-63. doi:10.1159/000066081.

24. Riches WG, Johnston WH. Primary adenomatous neoplasms of the middle ear: light and electron microscopic features of a group distinct from the ceruminomas. Am J Clin Pathol. 1982;77:153-61.

25. Stone HE, Lipa M, Bell RD. Primary adenocarcinoma of the middle ear. Arch Otolaryngol. 1975;101:702-5.

26. Gillanders DA, Worth AJ, Honore LH. Ceruminous adenoma of the middle ear. Can J Otolaryngol. 1974;3:194-201.

27. Lindqvist S, Bergstedt M. A case of ceruminoma (adenoma ceruminalis) of the middle ear. Pract Otorhinolaryngol (Basel). 1970;32:211-8.

28. Jan JC, Wang CP, Kwan PC, et al. Ceruminous adenocarcinoma with extensive parotid, cervical, and distant metastases: case report and review of literature. Arch Otolaryngol Head Neck Surg. 2008;134:663-6. doi:10.1001/archotol.134.6.663.

29. Hicks GW. Tumors arising from the glandular structures of the external auditory canal. Laryngoscope. 1983;93:326-40.
30. Cankar V, Crowley H. Tumors of the ceruminous glands. Cancer. 1964;17:67-75. doi:10.1002/1097-0142(196401)17:1<67::AIDCNCR2820170109>3.0.CO;2-A.

31. Wetli CV, Pardo V, Millard M, et al. Tumors of ceruminous glands. Cancer. 1972;29:1169-78. doi:10.1002/1097-0142(197205) 29:5<1169::AID-CNCR2820290507>3.0.CO;2-8.

32. Mashkevich G, Undavia S, Iacob C, et al. Malignant cylindroma of the external auditory canal. Otol Neurotol. 2006;27:97-101. doi:10.1097/01.mao.0000188352.97795.8c.

33. Pahor AL, O'Hara MD. Hidradenomata of the external auditory meatus (Review of the literature and report of a pleomorphic adenoma). J Laryngol Otol. 1975;89:707-20. doi:10.1017/ S0022215100080920.

34. Mansour P, George MK, Pahor AL. Ceruminous gland tumours: a reappraisal. J Laryngol Otol. 1992;106:727-32. doi:10.1017/ S0022215100120717.

35. Thompson LD, Nelson BL, Barnes EL. Ceruminous adenomas: a clinicopathologic study of 41 cases with a review of the literature. Am J Surg Pathol. 2004;28:308-18. doi:10.1097/00000478200403000-00003.

36. Heffner DK. Low-grade adenocarcinoma of probable endolymphatic sac origin: a clinicopathologic study of 20 cases. Cancer. 1989;64:2292-302. doi:10.1002/1097-0142(19891201)64:11<2292:: AID-CNCR2820641119>3.0.CO;2-\#.

37. Thompson LD. Neuroendocrine adenoma of the middle ear. Ear Nose Throat J. 2005;84:560-1.

38. Althaus SR, Ross JAT. Cerumen gland neoplasia. Arch Otolaryngol. 1970;92:40-2.

39. Bared A, Dave SP, Garcia M, et al. Mucoepidermoid carcinoma of the external auditory canal (EAC). Acta Otolaryngol. 2007;127:280-4. doi:10.1080/00016480600818120.

40. Brugler G. Tumors presenting as aural polyps: a report of four cases. Pathology. 1992;24:315-9. doi:10.3109/003130292090 68888.

41. Conlin PA, Mira JL, Graham SC, et al. Ceruminous gland adenoid cystic carcinoma with contralateral metastasis to the brain. Arch Pathol Lab Med. 2002;126:87-9.

42. Coyas A, Adamopoulos G. Cylindroma of the ear. J Laryngol Otol. 1966;80:860-2. doi:10.1017/S0022215100066081.

43. De Lucia A, Gambardella T, Carra P, et al. A case of highly aggressive adenoid cystic carcinoma of the external auditory canal. Acta Otorhinolaryngol Ital. 2004;24:354-6.

44. Donner LR, Ruff T, Diaz JA. Well-differentiated malignant cylindroma with partially preserved hyaline sheaths. A locally invasive neoplasm? Am J Dermatopathol. 1995;17:169-73. doi:10.1097/00000372-199504000-00009.

45. Fligiel Z, Kaneko M. Extramammary Paget's disease of the external ear canal in association with ceruminous gland carcinoma. A case report. Cancer. 1975;36:1072-6. doi:10.1002/10970142(197509)36:3<1072::AID-CNCR2820360334>3.0.CO;2-W.

46. Garbyal RS, Kumar M, Bohra A. Adenoid cystic carcinoma of ceruminous gland: a case report. Indian J Pathol Microbiol. 2006;49:587-9.

47. Goldman NC. Adenoid cystic carcinoma of the external auditory canal. Otolaryngol Head Neck Surg. 1992;106:214-5.

48. Iqbal A, Newman P. Ceruminous gland neoplasia. Br J Plast Surg. 1998;51:317-20. doi:10.1054/bjps.1997.0075.

49. Kim YH, Chae SW, Jung HH. Mucoepidermoid carcinoma arising from the eustachian tube and middle ear. J Laryngol Otol. 2003;117:202-4.

50. Koopot R, Reyes C, Pifarre R. Multiple pulmonary metastases from adenoid cystic carcinoma of ceruminous glands of external auditory canal. A case report and review of the literature. J Thorac Cardiovasc Surg. 1973;65:909-13.

51. Kosoy J, Jr Entzminger LB. Benign tumors of the external auditory canal. Tex Med. 1970;66:56-9. 
52. Lassaletta L, Patron M, Oloriz J, et al. Avoiding misdiagnosis in ceruminous gland tumours. Auris Nasus Larynx. 2003;30:28790. doi:10.1016/S0385-8146(03)00055-5.

53. Lynde CW, McLean DI, Wood WS. Tumors of ceruminous glands. J Am Acad Dermatol. 1984;11:841-7. doi:10.1016/ S0190-9622(84)80461-2.

54. Magliulo G, Fusconi M, Pulice G. Mucoepidermoid carcinoma of the external auditory canal: case report. Am J Otolaryngol. 2003;24:274-7. doi:10.1016/S0196-0709(03)00056-5.

55. Matthew RM, Subhashini J, Ponnaiya J, et al. Adenoid cystic carcinoma of the external auditory canal with pulmonary, renal and liver metastases. Indian J Cancer. 1997;34:139-42.

56. Mohan H, Handa U, Amanjit, et al. Adenoid cystic carcinoma of the external auditory canal. A case report with diagnosis by fine needle aspiration. Acta Cytol. 2003;47:792-4.

57. Nadasdy T, Kemeny E, Molnar G, et al. Adenocarcinoma of ceruminous glands. Ultrastructural, immunohistochemical and lectin histochemical studies. Acta Morphol Hung. 1991;39: 157-65.

58. Nyrop M, Grontved A. Cancer of the external auditory canal. Arch Otolaryngol Head Neck Surg. 2002;128:834-7.

59. Ray J, Worley GA, Schofield JB, et al. Rapidly invading sebaceous carcinoma of the external auditory canal. J Laryngol Otol. 1999;113:578-80. doi:10.1017/S0022215100144536.

60. Selcuk A, Ensari S, Cetin MA, et al. Ceruminous gland carcinoma of the external auditory canal presenting as chronic otitis media. B-ENT. 2007;3:195-9.

61. Sharma HS, Meorkamal MZ, Zainol H, et al. Eccrine cylindroma of the ear canal-report of a case. J Laryngol Otol. 1994;108:706-9.

62. Soh KB, Tan HK, Sinniah R. Mucoepidermoid carcinoma of the middle ear-a case report. J Laryngol Otol. 1996;110:249-51. doi:10.1017/S0022215100133328.

63. Soon SL, Bullock M, Prince ME. Ceruminous adenocarcinoma: a rare tumour of the external auditory canal. J Otolaryngol. 2001;30:373-7. doi:10.2310/7070.2001.19668.

64. Tanaka T, Saito R, Ishihara M, et al. Glandular tumors of the external auditory canal. Hiroshima J Med Sci. 1984;33:17-22.
65. Treasure T. External auditory canal carcinoma involving the temporomandibular joint: two cases presenting as temporomandibular disorders. J Oral Maxillofac Surg. 2002;60:465-9. doi:10.1053/joms.2002.31242.

66. Tzagaroulakis A, Pasxalidis J, Papadimitriou N, et al. Recurrent ceruminous adenocarcinoma of the external auditory canal. ORL J Otorhinolaryngol Relat Spec. 2003;65:300-2. doi:10.1159/ 000075230.

67. Nissim F, Czernobilsky C, Ostfeld E. Hidradenoma papilliferum of the external auditory canal. J Laryngol. 1981;95:843-8.

68. Dong F, Gidley PW, Ho T, et al. Adenoid cystic carcinoma of the external auditory canal. Laryngoscope. 2008;118:1591-6. doi:10.1097/MLG.0b013e31817c42a8.

69. Friedmann I. Pathological lesions of the external auditory meatus: a review. J R Soc Med. 1990;83:34-7.

70. Moore MG, Deschler DG, McKenna MJ, et al. Management outcomes following lateral temporal bone resection for ear and temporal bone malignancies. Otolaryngol Head Neck Surg. 2007;137:893-8. doi:10.1016/j.otohns.2007.09.010.

71. Choi JY, Choi EC, Lee HK, et al. Mode of parotid involvement in external auditory canal carcinoma. J Laryngol Otol. 2003;117:951-4. doi:10.1258/002221503322683821.

72. Okada T, Saito K, Takahashi M, et al. En bloc petrosectomy for malignant tumors involving the external auditory canal and middle ear: surgical methods and long-term outcome. J Neurosurg. 2008;108:97-104. doi:10.3171/JNS/2008/108/01/0097.

73. Kinney SE, Wood BG. Malignancies of the external ear canal and temporal bone: surgical techniques and results. Laryngoscope. 1987;97:158-64. doi:10.1288/00005537-198702000-00006.

74. Arriaga M, Curtin H, Takahashi H, et al. Staging proposal for external auditory meatus carcinoma based on preoperative clinical examination and computer tomography findings. Ann Otol Rhinol Laryngol. 1990;90:714-21.

75. Torske KR, Thompson LD. Adenoma versus carcinoid tumor of the middle ear: a study of 48 cases and review of the literature. Mod Pathol. 2002;15:543-55. doi:10.1038/modpathol.3880561. 